\title{
INHIBITION OF GERANYLGERANYL DIPHOSPHATE SYNTHESIS IN IN VITRO SYSTEMS
}

\author{
Andrea Steiger, Ursula Mitzka-Schnabel, Werner Rau, Jürgen Soll and Wolfhart Rüdiger
}

Botanisches Institut der Universität München, Menzinger Str. 67, 8000 München 19, W. Germany

(Revised received 24 September 1984)

\begin{abstract}
Key Word Index-Avena sativa; Gramineae; Cucurbita pepo; Cucurbitaceae; etiolated seedlings; endosperm; mevalonic acid; isopentenyl diphosphate.
\end{abstract}

\begin{abstract}
The incorporation of $\left[{ }^{14} \mathrm{C}\right]$ mevalonate and $\left[{ }^{14} \mathrm{C}\right]$ isopentenyl diphosphate into geranylgeranyl diphosphate was investigated in in vitro systems from Cucurbita pepo (pumpkin) endosperm and from Avena sativa etioplasts. Mevalonate incorporation was effectively inhibited in the pumpkin system by geranylgeranyl diphosphate and geranylgeranyl monophosphate but less effectively by phytyl diphosphate or inorganic diphosphate. Membrane lipids, geranyllinalool, or lecithin enhanced mevalonate incorporation in the Cucurbita system. Incorporation of isopentenyl diphosphate was also enhanced by lecithin and inhibited by geranylgeranyl diphosphate in the Cucurbita system. No lipid enhancement was found in the Avena system; inhibition by GGPP required a much higher GGPP concentration than in the Cucurbita system.
\end{abstract}

\section{INTRODUCTION}

The biosynthesis of GGPP has received considerable attention because it is the precursor of the biologically important diterpenes (e.g. gibberellins, phytol side chain of chlorophylls, phylloquinone, tocopherol) and tetraterpenes (carotenoids). Systems for in vitro synthesis of GGPP have been described for various organisms [1-11]. The biosynthetic pathway from MVA to GGPP is catalysed by several enzymes (MVA-kinase, 5-P MVA kinase, IPP isomerase, GG synthase) which are all soluble $[2,6,8,10,12]$. The last enzyme (GG synthase) was purified from a bacterial [2] and a plant source [6]; it catalyses the reaction of IPP with either DMAPP, GPP or FPP to GGPP. In none of these papers was the regulation of GGPP biosynthesis studied.

The biosynthesis of phytol which is closely connected to that of GGPP [13] is inhibited by PhPP [14]. This effect is attributed to feed-back inhibition because it has been demonstrated that mevalonate kinase is inhibited by PhPP [15]. PhPP and GGPP are very similar and therefore both are accepted by enzymes like chlorophyll synthetase [16]. GGPP is present in etiolated and green seedlings in about ten fold higher concentration than PhPP $[17,18]$. The GGPP pool of etiolated oat seedlings which is depleted during onset of chlorophyll biosynthesis seems to be reestablished only to a well-defined limiting value [18]. In pumpkin endosperm, only a limited ac-

Abbreviations: GGPP, geranylgeranyl diphosphate; PhPP, phytyl diphosphate; FPP, farnesyl diphosphate; MVA, mevalonic acid; IPP, isopentenyl diphosphate; DMAPP, dimethylallyl diphosphate; GPP, geranyl diphosphate; GL, geranyllinallool; Hepes, N-2-hydroxyethylpiperazine-N-2-ethanesulfonic acid; AMO 1618, 2-isopropyl-4-dimethylamino-5-methylphenyl-1piperidin-carboxylate-methylchloride; $35 \mathrm{KS}, 115 \mathrm{KS}, 35000 \mathrm{~g}$ or $115000 \mathrm{~g}$ supernatant. cumulation of GGPP is detected in vitro [U. MitzkaSchnabel and W. Rau, unpublished results].

In the study reported in this paper, we have investigated whether GGPP is able to regulate its own biosynthesis in in vitro systems from etiolated oat seedlings and from Cucurbita endosperm.

\section{RESULTS}

A cell-free system ( $35 \mathrm{KS}$ ) from the endosperm of immature seeds of $C$. pepo was able to convert MVA into several lipid compounds (Table 1). The product pattern shows that the bulk of isoprenoid lipids were derived from GGPP (kaurene, GG, carotenes) with only a small part of the lipids being derived from FPP (farnesol, squalene, sterols). In the presence of AMO 1618 the incorporation of MVA was strongly reduced. Although the lipid pattern was shifted by AMO 1618 towards the FPP products the larger part of the isoprenoid lipids were still derived from GGPP. It was to be expected, therefore, that GGPP rather than FPP was the main water-soluble product derived from MVA.

The production of $\left[{ }^{14} \mathrm{C}\right]$ GGPP from $\left[{ }^{14} \mathrm{C}\right] \mathrm{MVA}$ in the Cucurbita system was verified by isolation of GGPP by the method of Benz et al. [17] which basically comprises five chromatographic steps. It was more convenient, however, to hydrolyse GGPP in the aqueous layer after pre-extraction of lipophilic compounds with diethylether and then determine free GG and GL (see Experimental). This simple, indirect determination of GGPP could be used in this case since MVA metabolism in this in vitro systems does not lead to the production interfering compounds.

The GGPP synthesizing enzymes were localized in the $115000 \mathrm{~g}$ supernatant (Fig. 1). The slightly higher enzyme activity in the $35000 \mathrm{~g}$ supernatant might have been due to the presence of small amounts of enzymes in the membrane fraction but could equally as well be due to 
Table 1. Incorporation of $\left[{ }^{14} \mathrm{C}\right] \mathrm{MVA}$ into the unsaponifiable lipid fraction and the product pattern in the $35000 \mathrm{~g}$ supernatant $(3.0 \mathrm{ml})$ prepared from Cucurbita endosperm

\begin{tabular}{lcccccc}
\hline & \multicolumn{6}{c}{ Incorporation [nmol and (\%)] } \\
\cline { 2 - 7 } Incubation & Total & Farnesol & $\begin{array}{c}\text { Squalene } \\
\text { + sterols }\end{array}$ & GG & Kaurene & Carotenes \\
\hline conditions & 13.40 & 0.01 & 0.13 & 0.43 & 12.76 & 0.04 \\
- AMO 1618 & 100.0 & 0.1 & 1.0 & 3.2 & 95.2 & $0.3)$ \\
& 1.98 & 0.02 & 0.26 & 0.39 & 1.19 & 0.03 \\
+AMO 1618 & $(100.0$ & 1.0 & 15.0 & 19.9 & 60.4 & $1.7)$ \\
\hline
\end{tabular}

In the presence of AMO $1618(2 \mu \mathrm{M})$, the conversion of GGPP to kaurene was reduced. The in vitro system (final volume $3.75 \mathrm{ml}$ ) was incubated after addition of $229 \mathrm{nmol}(91.4 \mathrm{kBq})\left[{ }^{14} \mathrm{C}\right] \mathrm{MVA}$ at $27^{\circ}$ for $150 \mathrm{~min}$.

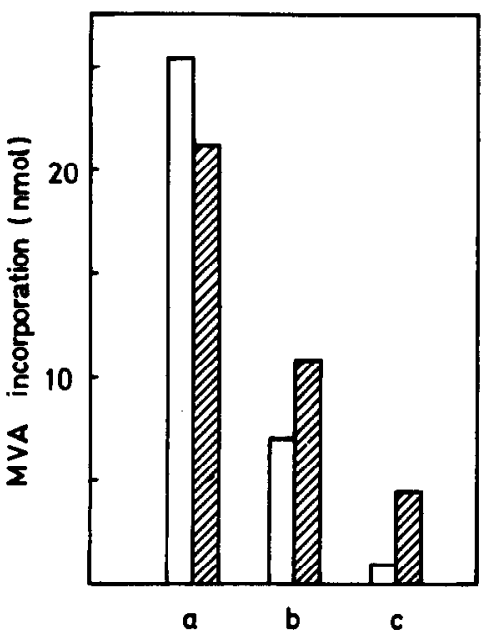

Fig. 1. Incorporation of $\left[{ }^{14} \mathrm{C}\right] \mathrm{MVA}$ into GGPP in vitro. The $35000 \mathrm{~g}$ supernatant (blank columns) or the $115000 \mathrm{~g}$ supernatant (hatched columns) were prepared from Cucurbita endosperm. Each sample containing $3 \mathrm{ml} 35 \mathrm{KS}$ or $115 \mathrm{KS}$ fraction of endosperm was incubated in the presence of $498 \mathrm{nmol}$ $(83.5 \mathrm{kBq})\left[{ }^{14} \mathrm{C}\right] \mathrm{MVA} \pm \mathrm{GGPP}$ (final volume $3.75 \mathrm{ml}$ ) at $27^{\circ}$ for $150 \mathrm{~min}$. The incubation was started by addition of the endosperm fraction. a, control without GGPP; b, addition of $8.25 \mathrm{nmol}$ GGPP (final conc. $2.2 \mu \mathrm{M}$ ); c, addition of $82.5 \mathrm{nmol}$ GGPP (final conc. $22 \mu \mathrm{M}$ )

enzyme activation by membrane constituents (see below). In both the $115000 \mathrm{~g}$ and $35000 \mathrm{~g}$ supernatants, the addition of GGPP reduced the incorporation of MVA into GGPP (Fig. 1). This effect was more pronounced in the $35000 \mathrm{~g}$ supernatant. This difference cannot be explained in a straightforward way since only in experiments with the $35000 \mathrm{~g}$ supernatant was the cyclase inhibitor AMO 1618 added to reduce further reactions of newly formed GGPP $[10,19]$. Addition of this inhibitor was not required in experiments with the $115000 \mathrm{~g}$ supernatant because most of the GGPP consuming membrane-bound enzymes had been removed. All subsequent experiments were performed with the $115000 \mathrm{~g}$ supernatant.

In order to test the specificity of the inhibitory effect of
GGPP upon its own biosynthesis, we also tested some structural analogues of GGPP (Table 2). GGMP had about the same effect as GGPP probably because of a kinase present in the soluble fraction which phosporylates GGMP to GGPP as described for oat etioplasts [16]. Less inhibition was found with PhPP whereas FPP showed a slight stimulation of GGPP synthesis. These results clearly demonstrated the structural specificity of GGPP inhibition. There may be several reasons for the stimulatory effect of FPP which inter alia can act as a C-15 precursor of GGPP. In order to elucidate the individual influence of the hydrophilic and the lipophilic part of GGPP, PhPP and FPP, we investigated the effect of inorganic pyrophosphate $\left(\mathbf{P P}_{\mathrm{i}}\right)$ and the tertiary alcohol GL which does not react with the kinase. The primary alcohol GG was not tested since like GGMP it reacts with the kinase [16]. Addition of $\mathbf{P P}_{i}$ showed a slight but significant inhibition whereas GL exhibited a pronounced stimulation of GGPP biosynthesis from MVA. Apart from the specific effect of GGPP, a general requirement for this inhibition seems to be the pyrophosphate group whereas the lipid part of these molecules seems to stimulate rather than to inhibit GGPP biosynthesis.

Lipid activation of membrane enzymes is a well-known phenomenon (review in ref. [20]). The possibility of lipid activation of GGPP biosynthesis was substantiated by the following experiment (Table 3). Lipids extracted from the membrane pellet obtained by centrifugation of the $35 \mathrm{KS}$

Table 2. Effect of GGPP and structural analogues upon the biosynthesis of GGPP from [ $\left.{ }^{14} \mathrm{C}\right] \mathrm{MVA}$ in the $115000 \mathrm{~g}$ supernatant from Cucurbita endosperm

\begin{tabular}{lccc}
\hline & & \multicolumn{2}{c}{ MVA incorporation } \\
\cline { 3 - 4 } Compound & $\begin{array}{c}\text { Concentration } \\
(\mu \mathrm{M})\end{array}$ & $(\mathrm{nmol})$ & $(\%$ control) \\
\hline & - & 5.52 & 100.0 \\
GGPP & 22 & 1.18 & 21.4 \\
GGMP & 22 & 0.76 & 12.7 \\
PhPP & 22 & 3.21 & 58.1 \\
FPP & 22 & 7.33 & 132.8 \\
PP & 150 & 3.58 & 64.8 \\
GL & 150 & 10.50 & 190.2 \\
\hline
\end{tabular}


Table 3. Effect of lipids upon the biosynthesis of GGPP from $\left[{ }^{14} \mathrm{C}\right] \mathrm{MVA}$ in the $115000 \mathrm{~g}$ supernatant from Cucurbita endosperm. For conditions see Fig. 1

\begin{tabular}{lccc}
\hline & $\begin{array}{c}\text { Concentration } \\
(\mu \mathrm{M})\end{array}$ & \multicolumn{2}{c}{ MVA incorporation } \\
\cline { 3 - 4 } Compound & - & 4.1 & 100 \\
\hline- & $\dagger$ & 12.1 & 295 \\
$\begin{array}{l}\text { 'Membrane } \\
\text { pellet'" }\end{array}$ & $\dagger$ & 28.1 & 685 \\
$\begin{array}{l}\text { Lipids from the } \\
\text { 'membrane pellet' }\end{array}$ & $\dagger$ & 31.2 & 760 \\
Lecithin & 150 & 30.1 & 734 \\
& 600 & control $)$ \\
\hline
\end{tabular}

*The 'membrane pellet' was prepared by centrifugation of $9.0 \mathrm{ml}$ of the $35000 \mathrm{~g}$ supernatant at $115000 \mathrm{~g}$ for $120 \mathrm{~min}$.

†The 'membrane pellet' from $9.0 \mathrm{ml} 35 \mathrm{KS}$ fraction (see *) or the lipids extracted therefrom, respectively, were added to the $115000 \mathrm{~g}$ supernatant $(3.0 \mathrm{ml})$.

fraction at $115000 \mathrm{~g}$ strongly enhanced GGPP synthesis. The membrane pellet itself showed less stimulation probably because substantial amounts of GGPP were further metabolized due to the lack of AMO 1618 in this experiment (see [10]). The pellet lipids could be substituted for by lecithin. The stimulation by lecithin was concentration dependent up to a saturation level (Fig. 2).

Under conditions of full enzyme activation, i.e. saturation of lecithin, the influence of GGPP upon its own biosynthesis was reassayed. As shown in Fig. 3, the inhibition of GGPP was more pronounced in the presence than in the absence of lecithin. These data clearly show that GGPP has, besides its specific inhibitory effect, a stimulatory 'lipid' effect.

The biosynthetic pathway from MVA to GGPP comprises several enzymes (MVA-kinase, 5-P MVA kinase, IPP isomerase, GGPP synthase). To determine whether the kinases or the isomerase and synthase respond to GGPP inhibition, the incorporation of IPP into GGPP was investigated (Table 4). GGPP formation from IPP was strongly inhibited by GGPP and enhanced by lecithin in the pumpkin system. Incorporation of IPP into GGPP only requires the enzymes IPP isomerase and GGPP synthase. Our results demonstrate that the site of regulation of overall enzyme activity is at these enzymes.

GGPP formation from IPP had also been demonstrated in chloroplasts $[8,9]$ and indirectly in etioplasts [21]. We therefore investigated GGPP biosynthesis from IPP in broken etioplasts in more detail. Substrate saturation was reached at $0.14 \mathrm{mM}$ IPP (data not shown). The optimal incubation time was $30 \mathrm{~min}$. Prolonged incubation decreased incorporation of IPP into GGPP probably due to further metabolization of GGPP. The influence of GGPP was tested at $0.14 \mathrm{mM}$ IPP and an incubation time of $30 \mathrm{~min}$ (Table 5). No significant difference from the control value was detected between 2.75 and $54.5 \mu \mathrm{M}$ GGPP. IPP incorporation was reduced by $50 \%$ only at the highest GGPP concentration tested $(170 \mu \mathrm{M})$. Lecithin did not enhance incorporation of IPP into GGPP in the oat etioplast system (Table 5).

\section{DISCUSSION}

GGPP an important precursor of di- and tetraterpenes can be labelled from ${ }^{14} \mathrm{C}$-labelled MVA or IPP using in vitro systems from oat etioplasts or Cucurbita endosperm. In order to find optimal incubation conditions, a knowledge of the characteristics of regulation of GGPP synthesis in these systems is essential. The results of such investigations might also give an indication of how GGPP synthesis is regulated in vivo.

The properties of the oat etioplast system are clearly different from the properties of the pumpkin endosperm system. The last enzymes of GGPP synthesis are not activated by lipids like lecithin. Inhibition by the product occurs only at a high concentration $(170 \mu \mathrm{M})$ of GGPP. This concentration is presumably higher than the physiological concentration in oat tissue which can be estimated roughly as follows:

The amount of GGPP has been estimated to be $16 \mathrm{nmol} / \mathrm{g}$ fr. wt [17] which is nearly identical with the protochlorophyllide content of $15 \mathrm{nmol} / \mathrm{g}$ fr. wt [22]. From data obtained with primary leaves of Phaseolus vulgaris [23], the etioplast volume can be calculated to be about $0.09 \mathrm{ml}$ per $\mathrm{g}$ fr. wt. Such data are not available for primary leaves of oat but it can be calculated from the data

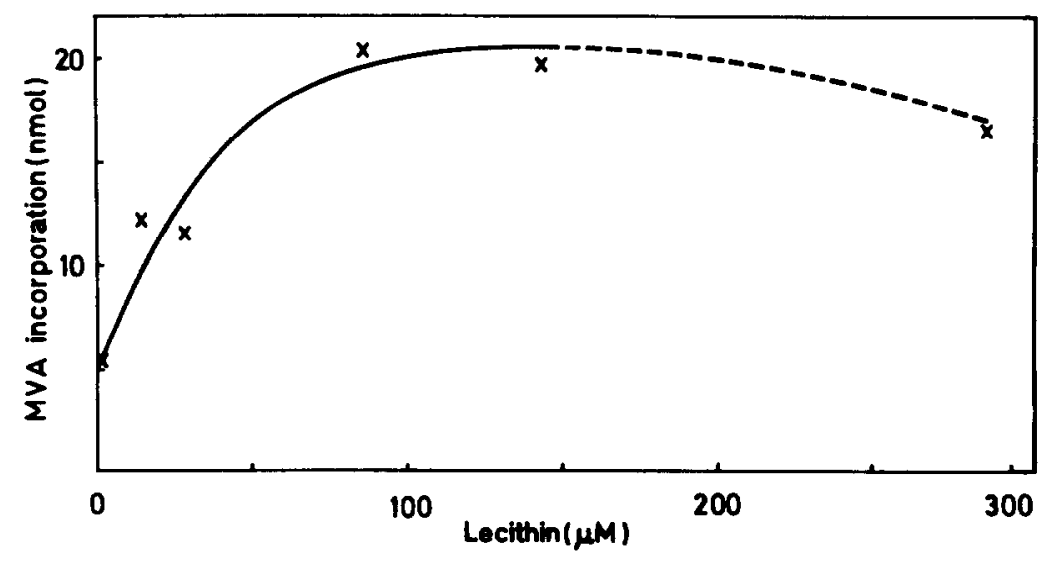

Fig. 2. Enhancement of $\left[{ }^{14} \mathrm{C}\right] \mathrm{MVA}$ incorporation into GGPP in the $115000 \mathrm{~g}$ supernatant prepared from Cucurbita endosperm by lecithin. Conditions of incubation as in Fig. 1. 


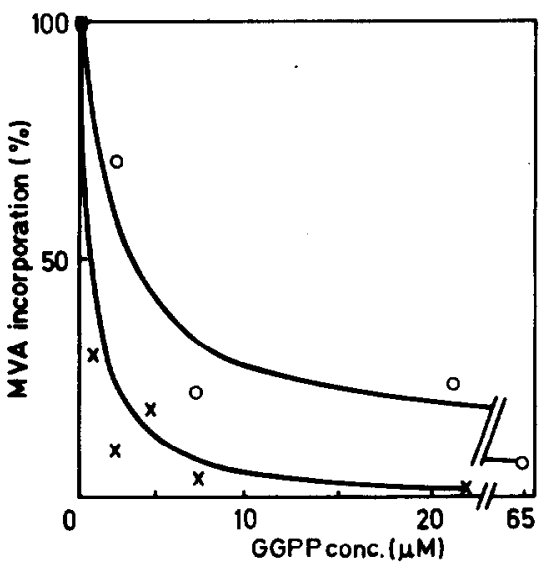

Fig. 3. Inhibition of $\left[{ }^{14} \mathrm{C}\right] \mathrm{MVA}$ incorporation into GGPP in the $115000 \mathrm{~g}$ supernatant prepared from Cucurbita endosperm by GGPP. $\bigcirc-0$, without lecithin, $495 \mathrm{nmol}$ (82 kBq) $\left[{ }^{14} \mathrm{C}\right]$ MVA were added per sample; $x-x$, with lecithin ( $350 \mathrm{nmol}$ per sample, final conc. $93 \mu \mathrm{M}$ ), $468 \mathrm{nmol}(37 \mathrm{kBq})$ $\left[{ }^{14} \mathrm{C}\right] \mathrm{MVA}$ were added per sample. Conditions of incubation as in Fig. 1.

Table 4. Effect of GGPP and lecithin upon the biosynthesis of GGPP from $\left[{ }^{14} \mathrm{C}\right] 1$ PP in the $115000 \mathrm{~g}$ supernatant from Cucurbita endosperm

\begin{tabular}{lccc}
\hline & & \multicolumn{2}{c}{ IPP incorporation } \\
\cline { 3 - 4 } Compound & $(\mu \mathrm{M})$ & $(\mathrm{nmol})$ & $(\%$ control $)$ \\
\hline & - & 12.5 & 100.0 \\
GGPP & 2.2 & 4.8 & 38.5 \\
GGPP & 22.0 & 1.4 & 10.9 \\
GGPP/Lecithin & $2.2 / 93$ & 14.2 & 115.6 \\
GGPP/Lecithin & $22.0 / 93$ & 3.8 & 30.4 \\
\hline
\end{tabular}

Conditions as in Fig. 1, except that $468 \mathrm{nmol}\left[{ }^{14} \mathrm{C}\right]$ IPP $(37 \mathrm{kBq})$ per sample were added instead of $\left[{ }^{14} \mathrm{C}\right] \mathrm{MVA}$.

Table 5. Incorporation of $\left[{ }^{14} \mathrm{C}\right]$ IPP into GGPP in broken etioplasts from $A$. sativa: influence of GGPP and lecithin

\begin{tabular}{lcc}
\hline Compound & $\begin{array}{c}\text { Concentration } \\
(\mu \mathrm{M})\end{array}$ & $\begin{array}{c}\text { Incorporation into GGPP } \\
(\% \text { control) }\end{array}$ \\
\hline Control & - & 100 \\
GGPP & 2.75 & 96.8 \\
& 5.5 & 117.3 \\
& 27.5 & 97.8 \\
& 54.5 & 104.5 \\
Lecithin & 170.0 & 50.3 \\
\hline
\end{tabular}

Each sample (final vol $3.0 \mathrm{~m}$ ) from the etioplast pellet derived from $10 \mathrm{~g}$ (fr. wt) primary leaves at $26^{\circ}$ for $30 \mathrm{~min}$.

of Lütz [24] that the total plastid volume per mesophyll cell is comparable in oat $\left(220 \mu \mathrm{m}^{3}\right)$ and bean $\left(190 \mu \mathrm{m}^{3}\right.$, recalculated from ref. [23]). Assuming an etioplast volume of $0.09 \mathrm{ml}$ per $\mathrm{g} \mathrm{fr}$. $\mathrm{wt}$, an overall concentration of $177 \mu \mathrm{M}$ GGPP can be calculated if the GGPP is restricted to the plastid. However, because GGPP can easily penetrate the plastid membrane $[25,26]$ it will be distributed within a much higher volume, i.e. the actual concentration of GGPP in the etioplasts will be much less than this.

The inefficient inhibition of GGPP formation should result in a high accumulation of GGPP, a property which could be used for preparation of labelled GGPP. However, oat etioplasts contain soluble and membranebound phosphatases which produce considerable amounts of free GG from GGPP, up to $30 \mathrm{nmol}$ GGPP/g fr. wt were hydrolysed [G. Jung and J. Benz, unpublished]. The production of large amounts of free GG instead of GGPP was also described for chloroplasts $[8,9]$.

The in vitro system of Cucurbita does not hydrolyse GGPP to any great extent; free GG can be detected only in traces. GGPP synthesis is enhanced 4-7 fold (Fig. 2 and Table 3) by polar lipids like lecithin and is inhibited some $80-97 \%$ by GGPP (Figs 1 and 3, Tables 2 and 4). The inhibition is specific for GGPP since structural analogues of GGPP show either a decreased inhibition or no inhibition (Table 2). Therefore, it can be assumed that this inhibition is due to 'product' rather than 'feed-back' inhibition since the last enzymes of the biosynthesis chain are concerned (Table 4). We assume that the last enzyme (GGPP synthase = prenyltransferase) is inhibited rather than IPP isomerase because a strong binding of GGPP to GGPP synthase had been described $[4,6]$ but this question is in need of further investigation.

\section{EXPERIMENTAL}

Preparation of the Cucurbita system. Fruits of Cucurbita pepo L. ('Gelber Zentner') were harvested when fully grown but still pale, from plants cultivated in the Botanical Garden. From the immature seeds the tips were cut off and the semi-liquid endosperm was squeezed out and frozen immediately at $-20^{\circ}$. $15-20 \mathrm{ml}$ endosperm was obtained per fruit; it could be stored frozen for up to 2 years without great loss of activity.

Preparation of the in vitro system provided by the semi-liquid endosperm of maturing seeds of pumpkin was essentially as in refs $[10,27]$. The thawed liquid endosperm was homogenized gently in a Potter-Elvehjem homogenizer and centrifuged either at $35000 \mathrm{~g}$ for $20 \mathrm{~min}$ or at $115000 \mathrm{~g}$ for $2 \mathrm{hr}$. A centrifugation time of $2 \mathrm{hr}$ was necessary to remove the bulk of the membranes. Aliquots ( $3 \mathrm{ml}$, each) of the resulting supernatants (35 KS or $115 \mathrm{KS}$, each containing $c a 18 \mathrm{mg}$ protein) were used as enzyme sources for the synthesis of $\left[{ }^{14} \mathrm{C}\right]$ GGPP in the presence of $\left[{ }^{14} \mathrm{C}\right] \mathrm{MVA}$ or $\left[{ }^{14} \mathrm{C}\right] \mathrm{IPP}$.

Incubation. The standard incubation mixture (total vol. $3.75 \mathrm{ml}$ ) contained: $2.6 \mathrm{mM} \mathrm{MgCl}_{2}, 0.5 \mathrm{mM} \mathrm{MnCl}_{2}, 0.5 \mathrm{mM}$ NADPH, $5.3 \mathrm{mM}$ ATP, an ATP-regenerating system $(0.5 \mathrm{mM}$ PEP; $100 \mu \mathrm{g}$ pyruvate kinase), $26.3 \mathrm{mM} \mathrm{KF}, 0.13 \mathrm{mM}$ [2$\left.{ }^{14} \mathrm{C}\right] \mathrm{MVA}(0.168$ or $0.079 \mathrm{kBq} / \mathrm{nmol})$ respectively $\left[{ }^{14} \mathrm{C}\right] \mathrm{IPP}$ $(0.079 \mathrm{kBq} / \mathrm{nmol})$. DL-MVA lactone was converted prior to incubation to its $\mathrm{K}$-salt with aq. $\mathrm{KOH}$ according to ref.[28]. Finally $3 \mathrm{ml} 35 \mathrm{KS}$ (natural $\mathrm{pH} 6.5$ ) or $115 \mathrm{KS}$ fraction of Cucurbita endosperm homogenate was added. When the $35 \mathrm{KS}-$ fraction was used as enzyme source the assay additionally contained 1 or $10 \mu \mathrm{M}$ AMO 1618. Incubations were performed in $18 \mathrm{ml}$ gas wash flasks for $150 \mathrm{~min}$ at $27^{\circ}$ under weak aeration. The incubations were terminated by heating the samples to $70^{\circ}$ for $10 \mathrm{~min}$. Any variations in the incubation conditions are given in the Results.

Lipids were extracted with $\mathrm{CHCl}_{3}$ from the 'membrane pellet' obtained by centrifugation of the $35 \mathrm{KS}$ fraction at $115000 \mathrm{~g}$ for 
$2 \mathrm{hr}$ (see Table 3). After addition of $50 \mu \mathrm{l} 1 \%$ Tween 20, the lipid soln was evaporated to dryness under a stream of $\mathbf{N}_{2}$ and the incubation mixture was added. For lipid dispersion the mixture was sonicated (Branson, sonic power, 3 times for $5 \mathrm{sec}$ ). Lecithin $\left(\mathrm{CHCl}_{3}\right.$-soln) was added in the same way.

Preparation of the Avena system. Seedlings of oat (Avena sativa L. cv. Pirol, Bayerische Futter- und Saatbau GmbH, München) were grown on moist vermiculite at $27-28^{\circ}$ for 7 days in the dark. The primary leaves $(100 \mathrm{~g})$ were homogenized with $200 \mathrm{ml}$ buffer (pH 7.5) containing $0.45 \mathrm{M} \mathrm{D-(-)-sorbitol,} 0.2 \%$

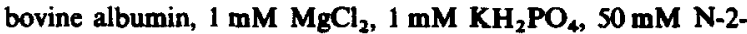
hydroxyethylpiperazine-N'-2-ethanesulfonic acid (HEPES), $1 \mathrm{mM} \mathrm{NaNO}, 1 \mathrm{mM} \mathrm{NaF}$ and $1 \mathrm{mM}$ ascorbic acid. The homogenate was filtered through a nylon net $(30 \mu \mathrm{m}$ mesh). The filtrate was centrifuged for $20 \mathrm{~min}$ at $6000 \mathrm{~g}$. The pellet which mainly consisted of etioplasts was suspended in $28 \mathrm{ml}$ buffer (pH 7.5) which contained $50 \mathrm{mM}$ HEPES, $4 \mathrm{mM} \mathrm{KH} \mathrm{KO}_{4}$, $10 \mathrm{mM} \mathrm{MgCl}_{2}, 10 \mathrm{mM} \mathrm{NaF}, 2 \mathrm{mM}$ ascorbic acid, $0.5 \mathrm{mM}$ $\mathrm{MnCl}_{2}, 1 \mathrm{mM}$ ATP, $1 \mathrm{mM}$ PEP, $1 \mathrm{mM}$ NADPH and $0.1 \mathrm{mg}$ pyruvate kinase. The etioplasts were disrupted at first in a Potter-Elvehjem homogenizer and then by exposure to ultrasound (Branson, sonic power, 3 times for $5 \mathrm{sec}$ ).

Incubation. Aliquots of the suspension $(2.8 \mathrm{ml}$ each) were incubated at $26^{\circ}$ for $30 \mathrm{~min}$ after addition of $\left[{ }^{14} \mathrm{C}\right] \mathrm{IPP}$ and, in some experiments, GGPP, lecithin and other compounds (see Table 5). The final vol was $3.0 \mathrm{ml}$. The incubation was terminated by heating the samples to $70^{\circ}$ for $10 \mathrm{~min}$. All steps were performed under dim-green safelight.

Purification of GGPP was essentially as in ref. [13]. Nonlabelled GGPP $(0.5 \mathrm{mg})$ was added to each sample. For hydrolysis of GGPP, the samples were acidified to $\mathrm{pH} 1.0$ with $\mathrm{H}_{2} \mathrm{SO}_{4}$, heated to $85^{\circ}$ for 10 min, and, after cooling, extracted with $\mathrm{Et}_{2} \mathrm{O}$ $(3 \times 3 \mathrm{ml})$ [13]. The identities of the radioactively labelled products with added GG and GL were determined by TLC on silica gel with $\mathrm{C}_{6} \mathrm{H}_{6}$-EtOAc (3:1). The radioactive bands in question were recovered from the TLC-plates by repeated extraction with $\mathrm{MeOH}$ and the label was quantitatively determined in a liquid scintillation counter. The data presented in the tables and figures are corrected for GG/GL recovery and are given as nmol MVA or IPP converted to GGPP per incubation.

\section{REFERENCES}

1. Nandi, D. L. and Porter, J. W. (1964) Arch. Biochem. Biophys. $105,7$.

2. Kandutsch, A. A., Paulus, H., Levin, E. and Bloch, K. (1964)
J. Biol. Chem. 239, 2507.

3. Jungalwala, F. B. and Porter, J. W. (1967) Arch. Biochem. Biophys. 119, 209.

4. Oster, M. O. and West, C. A. (1968) Arch. Biochem. Biophys. $127,112$.

5. Graebe, J. E. (1969) Planta 85, 171.

6. Ogura, K., Shinka, T. and Seto, S. (1972) J. Biochem. 72, 1101.

7. Johnson, J. H., Reed, B. C. and Rilling, H. C. (1974) J. Biol. Chem. 249, 402.

8. Block, M. A., Joyard, J. and Douce, R. (1980) Biochim. Biophys. Acta 631, 210.

9. Kreuz, K. and Kleinig, H. (1981) Planta 153, 578.

10. Mitzka-Schnabel, U. and Rau, W. (1981) Phytochemistry 20 , 63.

11. Kreuz, K., Beyer, P. and Kleinig, H. (1982) Planta 154, 66.

12. Arebalo, R. E. and Mitchel, E. D. Jr. (1984) Phytochemistry 23, 13.

13. Soll, J., Schultz, G., Rüdiger, W. and Benz, J. (1983) Plant Physiol. 71, 849.

14. Watts, R. B. and Kekwick, R. G. O. (1974) Arch. Biochem. Biophys. 160, 409.

15. Gray, J. C. and Kekwick, R. G. O. (1972) Biochim. Biophys. Acta 279, 290.

16. Rüdiger, W., Benz, J. and Guthoff, C. (1980) Eur. J. Biochem. $109,193$.

17. Benz, J. Fischer, I. and Rüdiger, W. (1983) Phytochemistry 22, 2801.

18. Benz, J., Haser, A. and Rūdiger, W. (1983) Z. Pflanzenphysiol. 111, 349.

19. Dennis, D. T., Upper, C. D. and West, C. A. (1965) Plant Physiol. 40, 948.

20. Sandermann, H. (1984) Trends in Biochem. Sci. 8, 408.

21. Benz, J. and Rüdiger, W. (1981) Z. Pflanzenphysiol. 102, 95.

22. Schoch, S., Lempert, K. and Rüdiger, W. (1977) Z. Pflanzenphysiol. 83, 427.

23. Kirk, J. T. O. and Tilney-Bassett, R. A. (1978) The Plastids, 2nd edn, pp. 724-725, Elsevier, Amsterdam.

24. Lütz, C. (1981) Protoplasma 108, 83.

25. Benz, J., Hampp, R. and Rüdiger, W. (1981) Planta 152, 54.

26. Benz, J., Lempert, U. and Rüdiger, W. (1984) Planta 162, 215.

27. Rau, W. and Mitzka-Schnabel, U. (1985) in Methods of Enzymology, Steroids and Isoprenoids (Law, J. H. and Rilling, H. C., eds.) 110, pp. 253-267.

28. Britton, G. and Goodwin, T. W. (1971) in Methods in Enzymology XVIII C (McCormick, D. B. and Wright, L. D., eds.), p. 654. Academic Press, London. 